\title{
Green Superlubrication by Hydrogen-Free Amorphous Carbon with Human Friendly Lubricants
}

\author{
Makoto Kano, ${ }^{*}$ Jean Michel Martin, ${ }^{1}$ and Maria Isabel De Barros Bouchet ${ }^{1}$ \\ Kano Consulting Office, 3-405, 4-2-1 Ryokuen, Izumi-ku, Yokohama, 245-0002 Japan \\ ${ }^{1}$ University of Lyon, 36 Avenue Guy de Collongue 69134 Écully CEDEX, France
}

(Received April 17, 2017; accepted May 22, 2017)

Keywords: diamond-like carbon, superlubrication, hydrogen-free amorphous carbon, ta-C, lubricant, oleic acid

Recently, many abnormal weather phenomena have been observed throughout the world. One reason for this is thought to be increasing amount of carbon dioxide gas in the atmosphere. Fuelsaving technologies have been increasingly required, especially for automobiles, to avoid global environmental destruction by stringently reducing the amounts of carbon dioxide gas generated and global resource depletion. Additionally, poisonous components such as phosphorus, sulfur, and chlorine in industrial lubricants are required to be decreased or eliminated so that they do not harm human health. Technologies for reducing friction by using environment-friendly materials are direct ways of minimizing environmental problems and improving human health. For automotive engine lubrication, the viscosity of the engine oil has been lowered to improve fuel economy. As the viscosity of engine oil decreases, the requirement of wear resistance for sliding engine components such as the cam follower and piston is becoming stricter. Therefore, diamond-like carbon (DLC) which has several advantages, such as being harmless to the human body because it consists of mainly elemental carbon, low friction properties, high wear resistance, and high corrosion resistance, is increasingly applied to the actual sliding parts in automotive engines. In particular, hydrogen-free amorphous carbon, tetrahedral amorphous carbon (ta-C), is becoming popular for application to the valve lifters and piston rings of mass-produced gasoline engines, because it exhibits a lower friction coefficient under engine oil lubrication compared with hydrogen-containing amorphous carbon (a-C:H). Additionally, ta-C shows superlubricity with human-friendly lubricants, such as oleic acid and glycerol. In this article, recent topics in the technology for applying DLC coatings onto automotive engine components are reviewed. The properties of reducing friction for each application are discussed briefly. The effect of engine oil additives on the friction properties of DLC coatings is also explained. Then, the superlowfriction properties achieved by combining DLC coatings and environment-friendly lubricants are introduced as a promising technology for future engine components. A superlow friction coefficient below 0.01 was obtained by a self-mated ta-C coating lubricated with oleic acid; a-C:H coating and the noncoated bearing steel (SUJ2) did not function well. These results suggest that automotive engine fuel economy can be improved markedly by using completely environmentfriendly materials. Recent fundamental research on the mechanism of superlubrication is introduced briefly. Judging from these advanced technical results, DLC coating technologies to 
address global environmental problems are promising for use with various components for many industries in addition to the automotive industry.

\section{Introduction}

One of the outstanding properties of diamond-like carbon (DLC) coatings is their great potential to reduce friction. In the technical paper entitled "Near-frictionless carbon coatings for use in fuel injectors and pump systems operating with low-sulfur diesel fuels", it was shown that hydrogenated amorphous carbon as a DLC coating showed superlow friction with a friction coefficient below 0.01 as measured in the sliding test under an inert amosphere such as dry nitrogen gas. ${ }^{(1-5)}$ This finding of the superior low-friction properties of DLC suggested that the effect of the atmosphere at the sliding interface was essential. This provided a strong impetus to find a new way to apply DLC coatings onto engine components under engine oil lubrication to better reduce friction. DLC coatings on the sliding parts of automotive components, such as valve lifters and piston rings, have increasingly improved wear resistance and reduced friction. The actual application of DLC coatings in the industry has increased both in production volume and the kinds of applications.

In the first part of this paper, several successful applications of DLC coatings on automotive sliding components are shown. The tetrahedral amorphous carbon (ta-C) coatings have been applied increasingly to valve lifters and piston rings to improve fuel economy by reducing friction. For engine components, the friction properties evaluated for actual engines are explained. Although the successful application of DLC coatings on mass-produced engine components has increased steadily, we are far from being able to use the excellent properties of DLC coatings for all possible applications. From this standpoint, there are several technical issues to be explored, such as the optimum combination of materials using environment-friendly materials to reduce friction and to clarify the fundamental mechanism of the phenomenon of superlow friction.

The goals of finding an optimum combination of environment-friendly materials to reduce friction and reducing mechanical friction in automotive engines have been vigorously pursued to improve fuel economy. Reducing the friction between the cam and follower is effective in this regard in the low engine speed range. A bucket-type DLC-coated valve lifter has been used in gasoline engines to drastically reduce engine friction. ${ }^{(6)}$ The ultralow friction property was obtained by using the hydrogen-free DLC, ta-C, lubricated with oil containing an ester (GMO: glycerol mono-oleate). ${ }^{(7,8)}$ For a future lubricant, Woydt proposed that polyalkylene-glycol (PAG), which has the same hydroxide functional group as GMO, could be applied to actual automotive engine oil as the environment-friendly lubricant. ${ }^{(9,10)}$ Therefore, the combination of ta-C and some type of ester and glycol as an optimally environment-friendly material can be expected to improve fuel consumption by reducing engine friction. Since we are approaching this goal, the second topic, which is evaluating the potentiality of the superlow-friction property by self-mated DLC with the environment-friendly fluid lubrication, is presented. A superlow friction coefficient below 0.01 was obtained applying the self-mated ta-C coating by the filtered arc deposition process with oleic acid lubrication.

From the standpoint of future aspects, it is expected that friction losses in passenger cars will be reduced by $61 \%$ in the long term (15-25 years) by taking advantage of new technology. ${ }^{(11)}$ It is most essential to reduce the friction between sliding components in gasoline engines, as indicated in Fig. 1. The technology of DLC coatings combined with a harmless lubricant is most promising to achieve this requirement. Additionally, the technology using DLC coatings combined with 


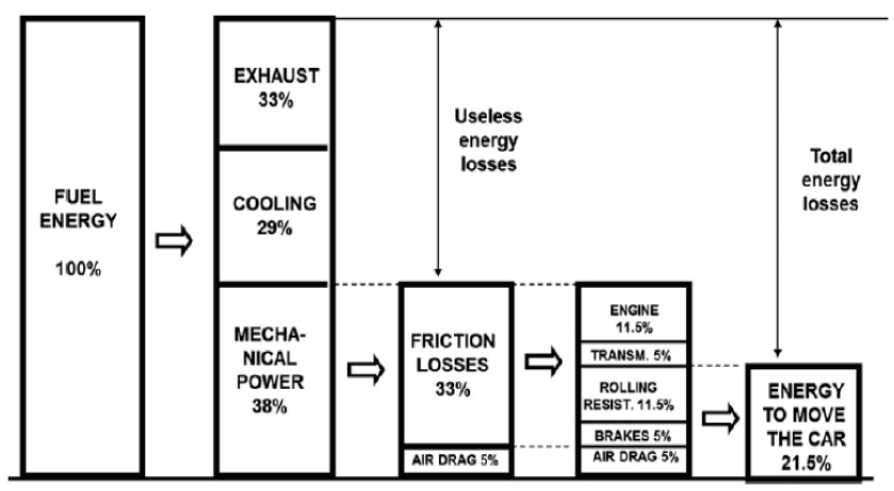

Fig. 1. Breakdown of passenger car energy consumption. ${ }^{(11)}$

environment-friendly lubricants has much potential to address environmental problems in various industries.

\section{DLC Coatings for Automotive Engine}

\subsection{Technology applied to engine components}

Recent applications of automotive components with DLC are shown in Table 1. In the last decade, the production volume and variety of coatings have increased markedly. The applications, except those for engine components, are used mainly to improve wear resistance.

Several applications for engine components are shown. For the application to the fuel injection systems for automotive engines, DLC was coated on several components such as the plunger of a high-pressure diesel fuel pump. As the sliding conditions of the fuel injector and pump components are increasing in severity owing to higher contact pressure, several types of DLC coatings were evaluated to obtain higher wear resistance under the boundary lubrication in fuels. ${ }^{(12)}$

The engine valve lifter is the most successful application of the DLC coating for a massproduced component because the fuel-saving effect is clearly observed when friction is reduced. In particular, the ta-C coating formed by arc ion plating via the physical vapour deposition (PVD) method has been adopted for the mass-produced gasoline engine to improve fuel economy, as shown in Fig. 2. The engine bench test using standard engine oil without molybdenum dithiocarbamate (MoDTC) additive was then conducted with an actual engine to examine the effect of the ta-C coating on reducing energy loss due to friction. The cylinder head was mounted on a test stand, and the camshaft made of chilled cast iron was driven directly by a drive motor via a torque meter, as shown in Fig. 3. Figure 4 shows the effect of various coatings on valve-train friction torque as a function of engine speed. ${ }^{(6)}$ The ta-C coating reduced friction torque by $45 \%$ compared with the result for a conventional phosphate coating on carburized steel at an engine speed of $2000 \mathrm{rpm}$. On the other hand, the friction-reducing effect of a-C:H was lower than that of ta-C and comparable to that of TiN.

Additionally, the ta- $\mathrm{C}$ coating has been applied increasingly to the piston rings for massproduced gasoline engines. Figure 5 shows the friction-reducing effect of the ta- $\mathrm{C}$ coating in the firing test using a single cylinder gasoline engine. ${ }^{(13)}$ The friction at the top ring with the ta-C 
Table 1

Automotive parts coated with DLC.

\begin{tabular}{|c|c|c|c|}
\hline \multicolumn{4}{|c|}{ Recent DLC applications on automotive sliding components } \\
\hline Applied parts & DLC & Coating & DLC property \\
\hline SUV 4WD torque controlled coupling clutch & $\mathrm{a}-\mathrm{C}: \mathrm{H}-\mathrm{Si}$ & PECVD & $\begin{array}{l}\text { Excellent friction property and } \\
\text { wear resistance }\end{array}$ \\
\hline SUV differential gear & WC/a-C:H & PECVD & $\begin{array}{c}\text { High wear resistance to increase } \\
\text { life of gear }\end{array}$ \\
\hline Fuel injector, pump & $\mathrm{a}-\mathrm{C}: \mathrm{H}$ & PECVD & $\begin{array}{l}\text { High wear resistance in fuel at } \\
\text { boundary lubrication }\end{array}$ \\
\hline Automotive engine piston pin & $\mathrm{a}-\mathrm{C}: \mathrm{H}$ & PECVD & $\begin{array}{l}\text { High wear resistance mating } \\
\text { with copper alloy bush }\end{array}$ \\
\hline Motorbike engine piston ring & WC/a-C:H & PECVD & $\begin{array}{l}\text { High wear resistance mating } \\
\text { with aluminum alloy of cylinder }\end{array}$ \\
\hline Automotive engine valve lifter & ta-C & PVD & $\begin{array}{c}\text { Ultralow friction and high wear } \\
\text { resistance }\end{array}$ \\
\hline Automotive engine piston ring & ta-C & PVD & $\begin{array}{l}\text { Ultralow friction and high wear } \\
\text { resistance }\end{array}$ \\
\hline
\end{tabular}

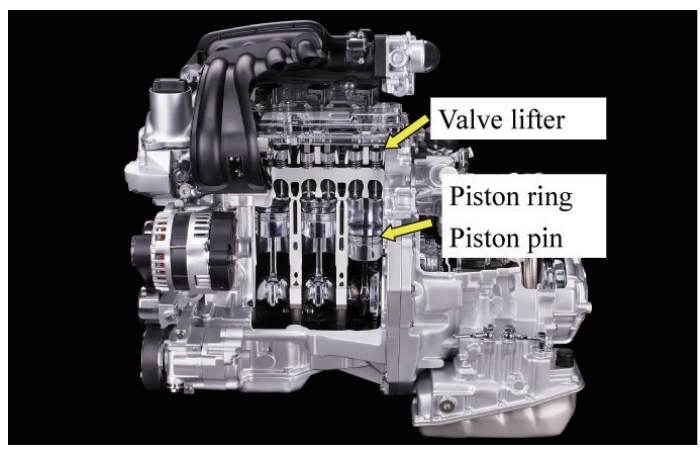

Fig. 2. (Color online) ta-C-coated components for gasoline engines.

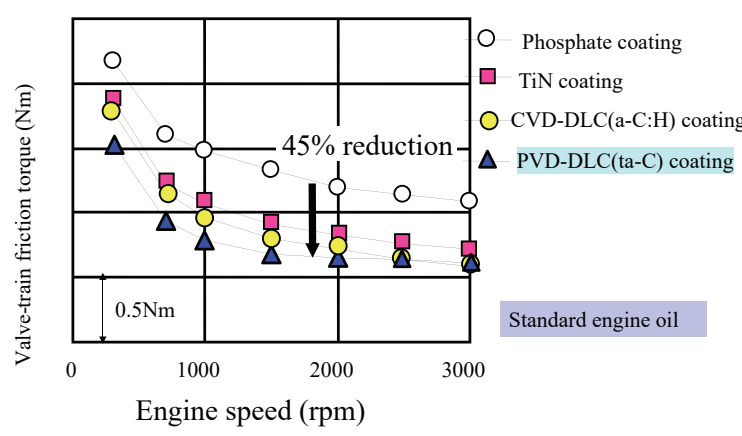

Fig. 4. (Color online) Friction reduction with ta-C coating.

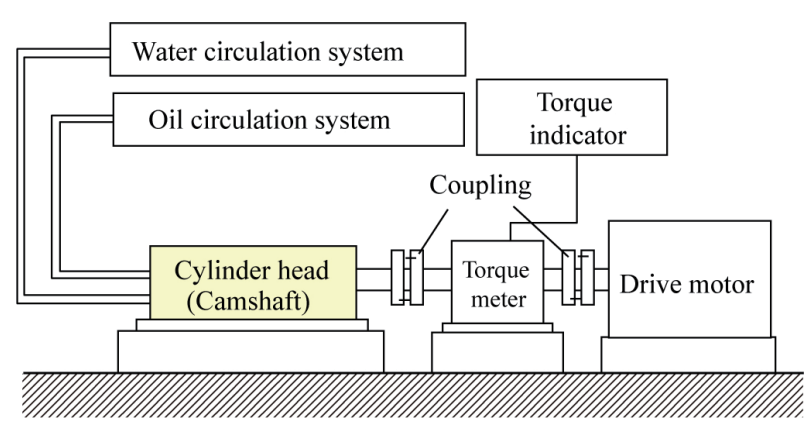

Fig. 3. (Color online) Automotive engine motoring test method.
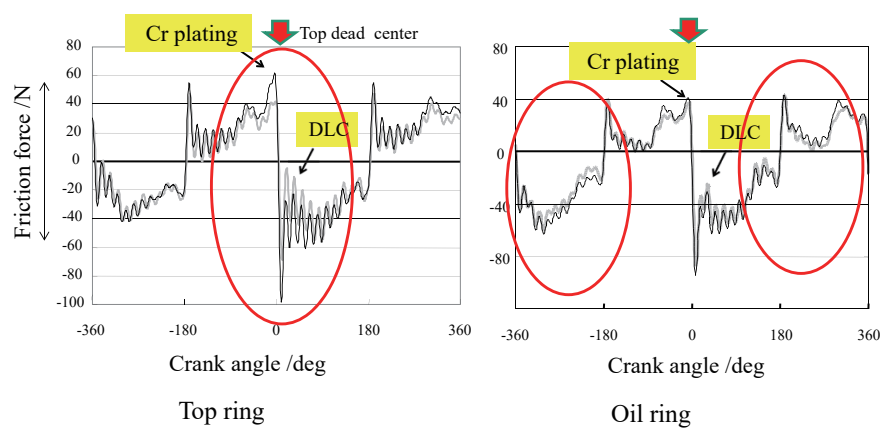

Fig. 5. (Color online) Friction reduction for ta-C coated piston ring.

coating, which was evaluated as the absolute value of the distance from zero on the horizontal line, was clearly lower than that of the conventional Cr-plated ring in the top dead-center region. For the ta-C-coated oil ring, the friction was lower than that of the Cr-plated ring in wide angle ranges except around the top dead-center and bottom dead-center regions. 
A similar superior effect of the ta- $\mathrm{C}$ coating on the engine piston ring compared with the a-C:H coating was also reported recently, as shown in Fig. $6 .^{(14)}$ Additionally, the ta-C coating has advanced properties of stability at high temperatures of around $400{ }^{\circ} \mathrm{C}$ and higher wear resistance under MoDTC-containing engine oil lubrication compared with those of a-C:H coatings. ${ }^{(15,16)}$ Because of these results, the application of the ta- $\mathrm{C}$ coating to engine piston rings to reduce friction is expected to increase.

\subsection{Effect of engine oil additives on friction with DLC}

Since all sliding engine components are usually lubricated with engine oil, it is very important to investigate the effect of engine oil additives on reducing friction.

The superlow-friction property of DLC coatings was affected by environmental conditions, as mentioned in the introduction. Studies were conducted first to evaluate the friction properties of DLC coatings under lubrication to find the additives essential to reduce friction most effectively. Because automotive engine oil contains many kinds of complex additives such as zinc dialkyl dithiophosphate (ZDDP), it was difficult to identify the interactions clearly between the additives and the DLC coating. ${ }^{(17-22)}$ The pin-on-disc sliding test was conducted to evaluate the effect of one simple modifier on the friction properties of DLC. As a typical DLC coating, hydrogenated amorphous carbon, a-C:H, and hydrogen-free tetrahedral amorphous carbon, ta- $\mathrm{C}$, were selected to be evaluated. The ta-C coating was applied to the polished carburized steel substrates to a thickness of $0.5 \mu \mathrm{m}$ from a graphite target by arc-ion plating by the PVD process and did not contain hydrogen. The a-C:H coating was applied to the substrates to a $1.0 \mathrm{~mm}$ thickness by a plasma-assisted chemical vapour deposition (CVD) process from hydrocarbon gas. It contained about 20 at. $\%$ of hydrogen. The sliding test was conducted at a high Hertzian pressure of $700 \mathrm{MPa}$ comparable to the actual maximum contact pressure at the cam follower under the oil lubrication at a temperature of $353 \mathrm{~K}$. Accordingly, we evaluated the effect of the friction modifier additives on the friction properties of DLC coatings when used with a poly-alpha-olefin (PAO)-based oil. Many types of friction modifier additives were examined, including amine, amide and ester (GMO). It was found that a PAO oil containing 1 mass $\%$ of ester (PAO + GMO) combined with a ta-C/steel pair showed an ultralow friction coefficient of 0.02 , while an a-C:H/steel pair displayed a much higher friction coefficient of 0.11 , and that of a steel/steel pair was 0.13 , as shown in Fig. $7 .{ }^{(23)}$

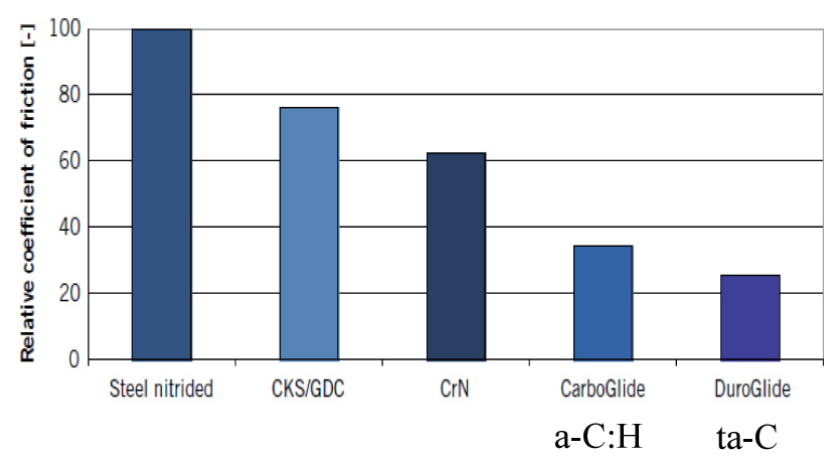

Fig. 6. (Color online) Lower friction of ta-C-coated ring compared with that of a-C:H.

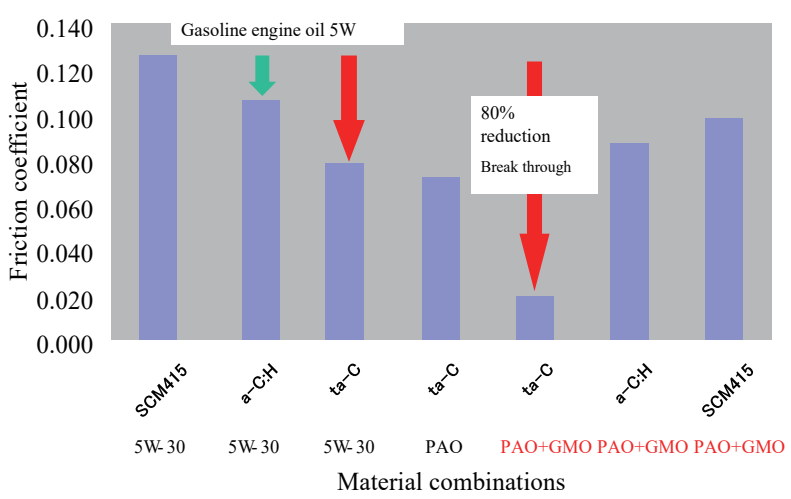

Fig. 7. (Color online) Ultralow friction property of ta-C under GMO-containing oil lubrication. 
GMO has two hydroxide $(-\mathrm{OH})$ functional groups. It was estimated that the chemical adsorption of this fuctional group on the ta-C coating surface generated the ultralow friction phenomenon in Fig. 7. Accordingly, the friction properties of DLC couples lubricated with PAO + GMO and glycerol of pure alcohol at $353 \mathrm{~K}$ were also evaluated by the linear-oscillation (SRV) test to clarify the reason for the ultralow friction. Figure 8 shows the friction coefficients of different kinds of material combinations lubricated with $\mathrm{PAO}+\mathrm{GMO}$ and pure glycerol. ${ }^{(23)}$ Amazing results were obtained for the ta-C/ta-C combination. The friction coefficients of the ta- $\mathrm{C}$ couples were substantially lower than those of the a-C:H ones. These results strongly suggest that the superlowfriction phenomenon was achieved by the interaction between the ta- $\mathrm{C}$ coating and the estercontaining oil and is certainly due to the formation of a very thin and low-shear-strength tribofilm on the ta-C sliding surface and better lubrication conditions. Moreover, outstanding superlowfriction and zero-wear behaviour were obtained for the ta-C/ta-C combination lubricated with pure glycerin at $80^{\circ} \mathrm{C}$. As shown in Fig. 8, the friction coefficient was below 0.01 and was actually not measurable with the equipment at hand. Moreover, no wear scar was visible by optical microscopy. This result suggests that the superlubricity is related to the alcohol functional group $(\mathrm{OH})$, which is common to both GMO and glycerol molecules. ${ }^{(24)}$

The friction coefficients of ta-C(DLC) and steel by the SRV test for the two kinds of fullformulated engine oil used at different running distances are shown in Fig. 9. ${ }^{(25)}$ Judging from this figure, the very low friction property of ta-C under the ester (GMO)-containing engine oil (Ashless oil) had been maintained over $5000 \mathrm{~km}$, although that of the steel under the MoDTC-containing engine oil increased considerably over $5000 \mathrm{~km}$. The latter result showed that the solid lubricant film, $\mathrm{MoS}_{2}$ formed on the steel sliding surface derived from MoDTC was consumed with a longer running distance. Therefore, it is suggested that the former result of maintaining low friction coefficients for longer distances may be caused by a mechanism different from that forming the solid lubricant film.

From autumn 2006, the ta-C-coated valve lifter along with the new gasoline engine oil containing GMO has been applied to mass-produced V6 gasoline engines. This new material technology could reduce fuel consumption by a few percent.

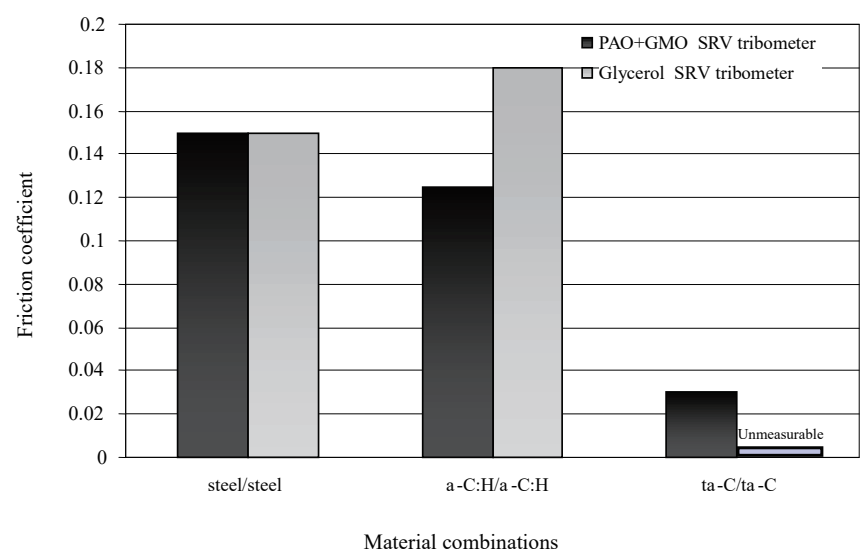

Fig. 8. Superlow friction of self-mated ta-C under glycerol lubrication.

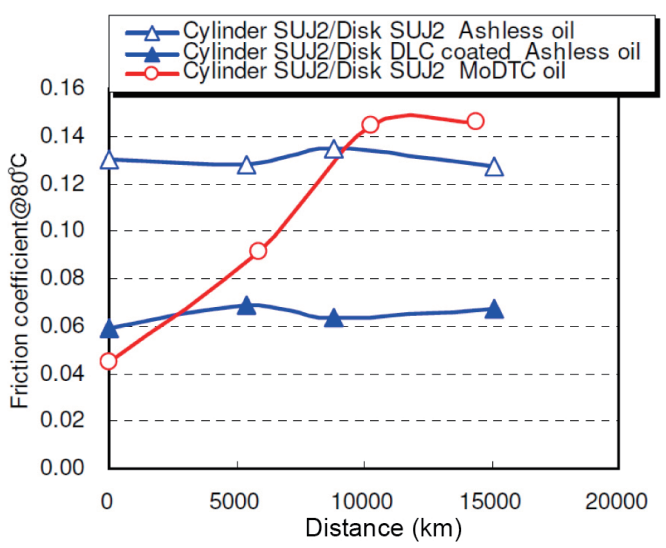

Fig. 9. (Color online) Results of SRV friction test on oils after driving test. 
Although the successful application of DLC coatings on mass-produced engine components has increased steadily and some level of understanding of the friction property of DLC coatings under lubrication has been achieved, there are still technical issues to be resolved such as the optimum combination of materials to reduce friction. Recently, the superlow-friction properties of ta-C coating pairs under oleic acid lubrication at ambient temperature have been clarified. ${ }^{(26)}$ Oleic acid has the other type of the functional group, the carboxylic acid $(-\mathrm{COOH})$. Additionally, a mechanism for this superlow-friction phenomenon has been proposed on the basis of the results of advanced surface analysis and supporting simulations.

\section{Superlow Friction Obtained by DLC-DLC Pairs with Oleic Acid Lubrication}

\subsection{Experimental methods}

As a second topic, fundamental research on the optimum combination of materials for DLC coatings and simple lubricants to reduce friction was introduced. ${ }^{(26)}$ Pin-on-disc rotating sliding tests were conducted in the following manner. The pins, measuring $9 \mathrm{~mm}$ in diameter and $9 \mathrm{~mm}$ in length, were made of hardened bearing steel (AISI52100) and polished to a surface roughness below $0.05 \mathrm{~mm}$. The discs measured $33 \mathrm{~mm}$ in diameter and $3 \mathrm{~mm}$ in thickness and were made of AISI52100 and polished to a surface roughness below Ra $0.05 \mu \mathrm{m}$. Two kinds of DLC were coated on the discs and pins. The a-C:H coating (hydrogen content of approximately 20 at.\%) was deposited by plasma-enhanced CVD to $1 \mu \mathrm{m}$ thickness, and the ta-C(T) coating was deposited by the T-shaped filtered arc PVD process ${ }^{(27)}$ to $0.3 \mu \mathrm{m}$ thickness. These specifications are summarized in Table 2. The surface roughness $(R a)$ for the discs was almost the same and below $10 \mathrm{~nm}$. The pin was secured to prevent it from rotating and was pressed against the rotating disc, as shown in Fig. 10. Contact at the sliding interfaces was in the shape of a line under a high Hertzian pressure of $70 \mathrm{MPa}$.

Before starting to slide, a few droplets $(0.01 \mathrm{ml})$ of the lubricant were provided to gently wet the disc. This quantity is sufficient to form a visible meniscus between the cylinder and the flat disc and can feed the contact area under good conditions. The temperature of the entire system was fixed at ambient temperature $\left(25^{\circ} \mathrm{C}\right.$ ) and the test was performed in ambient air (around $50 \% \mathrm{RH}$ ).

First, a "decreasing speed test" was performed. The speed was progressively reduced step by step from 100 to $0.01 \mathrm{~mm} / \mathrm{s}$, with holding for $5 \mathrm{~min}$ at each speed. This method of decreasing speed was designed to keep the smooth surface on the sliding track initially by starting to slide under mild conditions towards the mixed-lubrication regime. The results were expected to clarify

Table 2

Specifications of cylinder and disc samples for sliding tests.

\begin{tabular}{lccc}
\hline & Steel (uncoated) & a-C:H & ta-C \\
\hline Coating method & & PECVD & (PVD filtered arc) \\
Coating thickness $(\mu \mathrm{m})$ & & 1.1 & 0.3 \\
Disc roughness $R a(\mathrm{~nm})$ & 2.6 & 4.2 & 3.7 \\
Cylinder roughness $R a(\mathrm{~nm})$ & 12 & 14.4 & 16.1 \\
Surface hardness $(\mathrm{GPa})$ & 10 & 20 & 61 \\
Young modulus $(\mathrm{GPa})$ & 200 & 190 & 650 \\
\hline
\end{tabular}




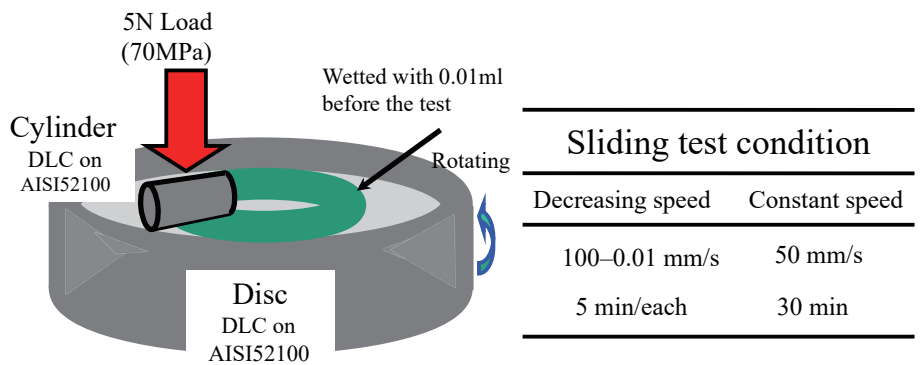

Fig. 10. (Color online) Rotating sliding test method and sliding condition (ref friction).

the different friction properties between a-C:H and ta- $\mathrm{C}$ coatings with respect to the sliding speed and the two lubricants used.

Second, the "constant sliding speed test" was conducted at $50 \mathrm{~mm} / \mathrm{s}$ for $30 \mathrm{~min}$ under oleic acid lubrication to focus on tribofilm formation when the superlow-friction regime was reached. The other sliding tests used the same test conditions and were conducted using new friction pairs to investigate the difference in tribofilm chemistry on the sliding tracks for a-C:H and ta- $\mathrm{C}$ discs by several analyses. The oleic acid with a deuterated carboxylic functional group was used to find evidence of tribochemical reactions by time-of-flight secondary ion mass spectrometry (ToF-SIMS) analysis.

\subsection{Results and discussion}

\subsubsection{Friction properties in the "decreasing sliding speed" tests}

Figure 11 shows the friction results of DLCs and steel surfaces lubricated by 1-hexadecene and oleic acid during decreasing sliding speed tests from 100 to $0.01 \mathrm{~mm} / \mathrm{s}^{(26)}$ These results have the shape of a Stribeck curve showing the different regimes that are encountered, namely, elastohydrodynamic lubrication (EHL) above $100 \mathrm{~mm} / \mathrm{s}$, boundary lubrication (BL) under $1 \mathrm{~mm} / \mathrm{s}$, and mixed between these two speeds.

For steel surfaces, friction in the presence of 1-hexadecene was much higher than that for those with DLCs and increased above 0.3 when sliding speed was decreased below $1 \mathrm{~mm} / \mathrm{s}$. Therefore, the sliding test for the steel was stopped at this speed. For oleic acid, the different friction coefficients of DLCs below $5 \mathrm{~mm} / \mathrm{s}$ seemed to occur under boundary lubrication conditions, whereas those above $50 \mathrm{~mm} / \mathrm{s}$ seemed to occur in the EHL lubrication regime. The friction coefficient under 1-hexadecene lubrication for ta-C(T) below $1 \mathrm{~mm} / \mathrm{s}$ was much higher than that for a-C:H. In constrast, the friction coefficient for ta-C(T) above $50 \mathrm{~mm} / \mathrm{s}$ was much lower than that for a-C:H (in the EHL regime).

For oleic acid lubrication, the friction coefficients for all friction pairs decreased significantly compared with those in the presence of 1-hexadecene. The friction coefficient under oleic acid lubrication for ta-C(T) below $1 \mathrm{~mm} / \mathrm{s}$ and above $50 \mathrm{~mm} / \mathrm{s}$ was much lower than those for both $\mathrm{a}-\mathrm{C}: \mathrm{H}$ and steel combinations. It was found that the effect of reducing friction for ta- $\mathrm{C}(\mathrm{T})$ in the presence of the carboxylic group $\mathrm{COOH}$ was much stronger than that for a-C:H. Additionally, for ta- $\mathrm{C}(\mathrm{T})$, the friction curve under oleic acid lubrication was very different from that under 

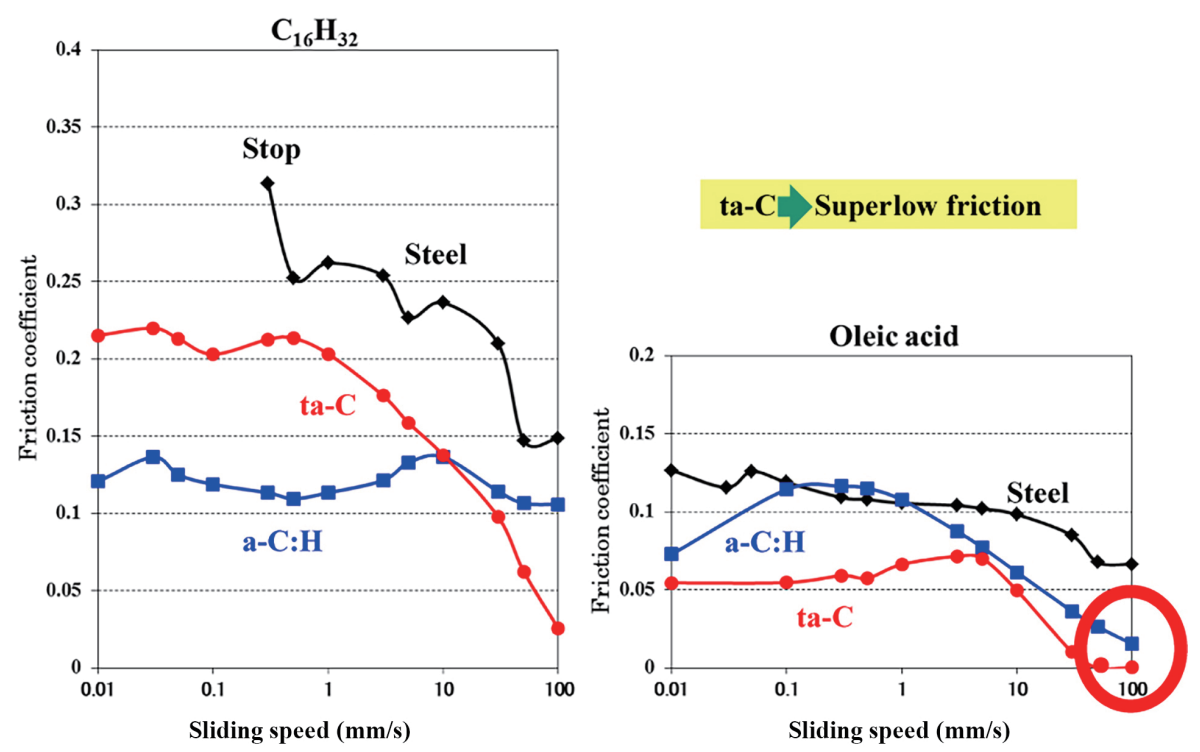

Fig. 11. (Color online) Results of measuring friction in decreasing sliding speed tests (ambient temperature).

1-hexadecene lubrication. Judging from these results, the ultralow friction coefficient for ta- $\mathrm{C}(\mathrm{T})$ under sliding conditions with oleic acid lubrication below $1 \mathrm{~mm} / \mathrm{s}$ sliding speed belongs to the boundary lubrication regime and seems to be caused by the formation of a very low shear strength tribofilm. Alternatively, a-C:H coatings are better lubricated by hydrocarbons (alkanes or alkenes) with no oxygen-containing functions. Briefly, it is suggested that a-C:H is well lubricated by hydrocarbon lubricants, whereas ta-C(T) prefers $\mathrm{COOH}$-containing lubricants to reduce friction.

In contrast, the superlow friction coefficient of around 0.005 for ta-C(T) above $50 \mathrm{~mm} / \mathrm{s}$ sliding speed belongs to the very thin-film EHL lubrication regime and is certainly caused by another mechanism. An estimation of the maximum film thickness using Dowson's equation gives a value of $15 \mathrm{~nm}$, and a lambda ratio of 4 . One possible mechanism is that the ratio of fluid lubrication increases drastically when wettability is improved, and slips at the wall may occur.

\subsubsection{Friction properties of "constant sliding speed" tests and surface analysis}

The constant sliding speed tests were conducted several times for ta-C(T) and a-C:H under deuterated oleic acid $\left(\mathrm{C}_{18} \mathrm{H}_{33}{ }^{2} \mathrm{H}_{1} \mathrm{O}_{2}\right)$ lubrication for $30 \mathrm{~min}$. to obtain two similar samples for analysis under the same sliding conditions. For ta-C(T) (see Fig. 12), the friction coefficient decreased after only $60 \mathrm{~s}$ and was well below 0.01 , and the regime was kept to an average value of around 0.005 for at least $1800 \mathrm{~s}$. On the other hand, friction for a-C:H decreased slowly to around 0.045 and did not reach the superlow regime.

After the other sliding tests were conducted under the same conditons where the superlowfriction properties of ta- $\mathrm{C}(\mathrm{T})$ pairs were reproduced, the remaining lubricant and any wear debris on the cylinders and discs were removed by ultrasonic cleaning with n-heptane. One sample was dedicated to ToF-SIMS analysis and the other was used for fine surface analysis using highresolution synchrotron radiation photoemission (HRPES) together with soft X-ray absorption 


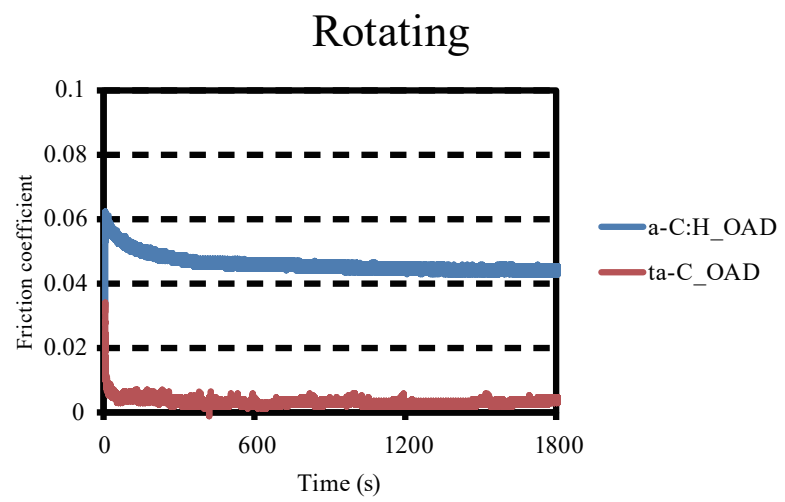

Fig. 12. (Color online) Superlow-friction properties of ta-C(T) pair under oleic acid lubrication.

spectroscopy (XAS).

A selected static ToF-SIMS image on the sliding track for the ta-C(T) disc is displayed in Fig. 13. ${ }^{(26)}$ For this sliding test, oleic acid, which has a deuterated carboxyl functional group -COOD, was used to evaluate the tribochemical reaction on the ta-C(T) sliding surface. The ion maps were reconstructed from SIMS spectra acquired for each pixel of the scanned zone. In the figure, the intensity in the images corresponds to the number of selected molecular ions in spectra obtained from pixels of $\mathrm{COD}^{-}$. Typically, black indicates no signal and yellow indicates a high intensity of ions. In the images, it is observed that the worn surface is not perfect and has a flat part with a plateau shape of the mated cylinder (drawn in white in the $\mathrm{COD}^{-}$image) of around $5 \mathrm{~mm}$ in length and a few microns in height. This distance between the edges fit well with that of the two rings in the images. Judging from this result, the rings in the ToF-SIMS images seemed to be formed by the tribochemical reaction occurring only in the real contact parts of the linear contact. Judging from this image, the sliding surface of the ta- $\mathrm{C}(\mathrm{T})$-coated surface under oleic acid lubrication seemed to be adsorbed by a hydroxyl $(-\mathrm{OH})$, which must be derived from the carboxylic acid functional group. This result suggests that the superlow-friction phenomenon of ta-C(T) under oleic acid lubrication was generated by forming the same type of tribo-chemical-reacted surface of the ta-C coating under GMO and glycerol lubrication.

The fine surface analysis was carried out using high-resolution photoemission spectrosopy (PES) and soft X-ray absorption spectroscopy (XAS) analyses on the ta-C(T) cylinder surface after the constant speed sliding tests to gain deeper insights on the nanometer scale. ${ }^{(28)}$ The detailed examination of the C1s spectrum outside the wear scar revealed domination by only one contributing peak at $285.5 \pm 0.2 \mathrm{eV}$ with an FWHM of $1.09 \pm 0.2 \mathrm{eV}$, attributed to $\mathrm{sp}^{3}$ carbons present on the ta- $\mathrm{C}(\mathrm{T})$ surface (including $\mathrm{C}-\mathrm{C}$ and/or $\mathrm{C}-\mathrm{H}$ ), as shown in Fig. 14. ${ }^{(28)}$ Inside the wear scar, the C1s peak is clearly shifted by $0.5 \mathrm{eV}$ towards a lower binding energy and it required two contributions to be fit. The result of the optimal fitting confirms that inside the scar, the first contribution is at $284.6 \mathrm{eV}$ with an FWHM of $0.7 \pm 0.1 \mathrm{eV}$ and the second one is at $285.2 \pm 0.2 \mathrm{eV}$ with an FWHM of $0.8 \pm 0.1 \mathrm{eV}$. The contribution at $284.6 \mathrm{eV}$ can be assigned to the presence of pure $\mathrm{sp}^{2}$ carbon, as in graphene, nonplanar carbon sheets, or graphite. Figure 15 shows the nearedge X-ray absorption fine structure (NEXAFS) spectra of the C K-edge recorded outside and inside the wear scar. ${ }^{(28)}$ Figure 15 (b) is focused on the transitions observed between 285 and 290 


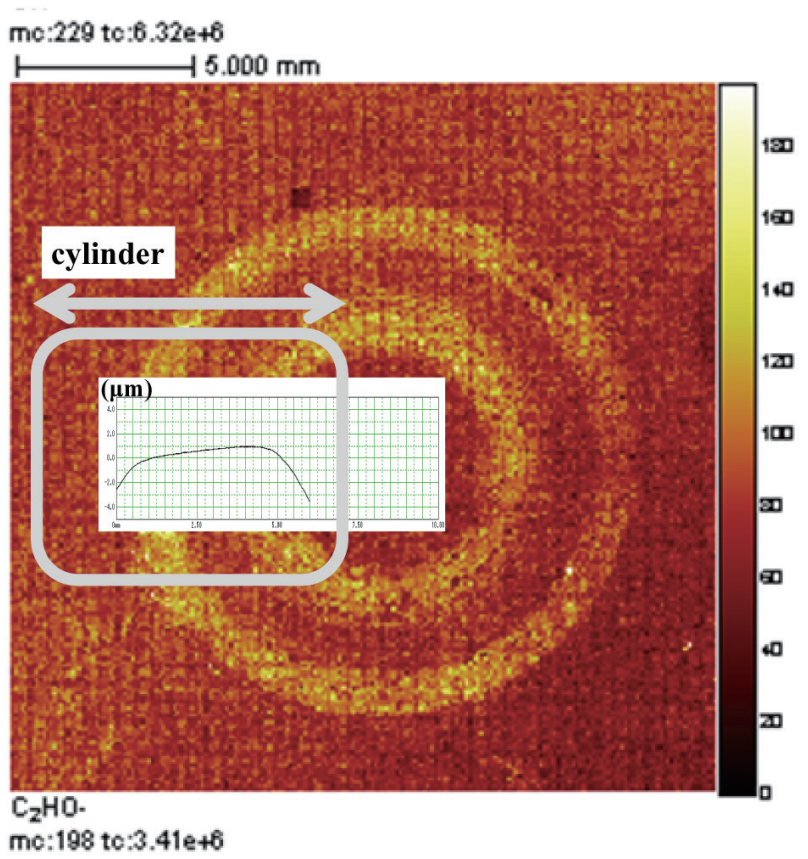

Fig. 13. (Color online) ToF-SIMS image of $\mathrm{COD}^{-}$ on sliding tracks for ta-C(T) disc.

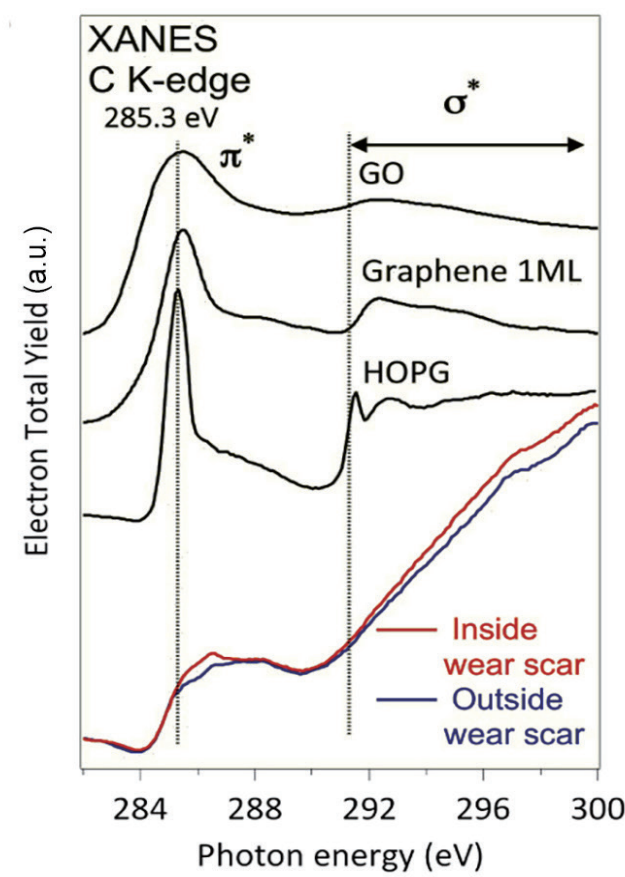

(a)

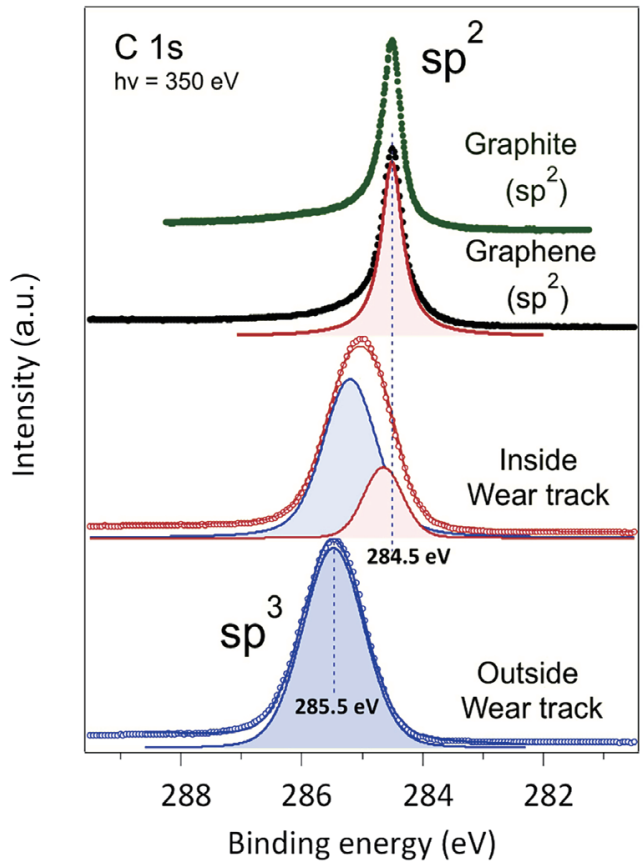

Fig. 14. (Color online) C1s PES spectra recorded inside and outside the ta-C(T) wear scar using incident $h v=350 \mathrm{eV}$. At the top of the figure, the spectra of graphite and graphene samples are also shown as a reference for pure $\mathrm{sp}^{2}$ carbon.

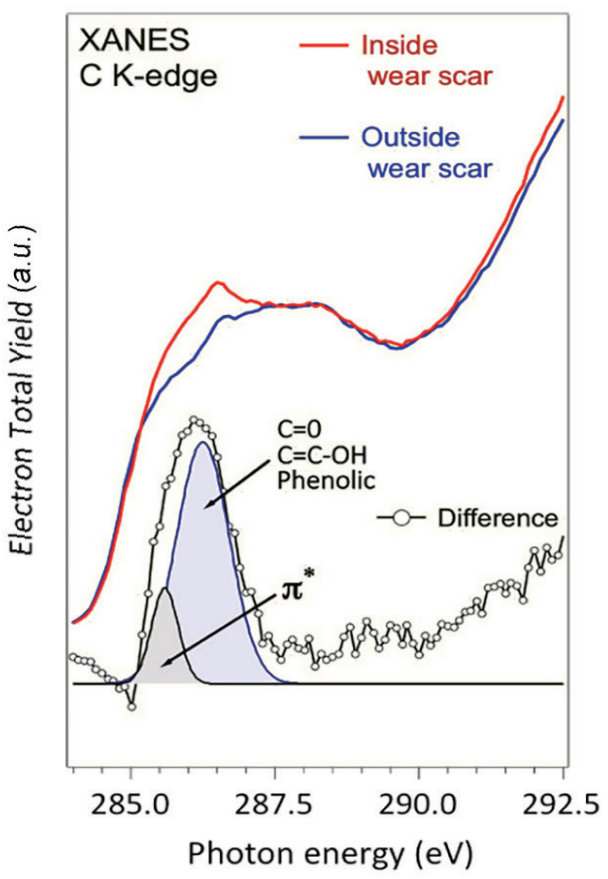

(b)

Fig. 15. (Color online) (a) XAS spectra of the C K-edge inside and outside the wear scar. At the top of the figure, the spectra of graphite and graphene oxide samples are plotted. (b) Spectrum showing the difference is fitted to show the different components. 
eV. The difference clearly shows that two main contributions are enhanced inside the wear scar: the $1 \mathrm{~s}-\pi$ transitions corresponding to $\mathrm{sp}^{2}$ carbon near $285 \mathrm{ev}$ and the contribution at approximately $286.5 \mathrm{eV}$, which typically represents the energies of the $1 \mathrm{~s}-\sigma^{*}$ transitions that correspond to oxygen-derived species such as alcohol and phenolic species.

Hence, by combining PES and XAS analyses, indications are strong that the ta-C(T) surface lubricated with oleic acid becomes an amorphous $\mathrm{sp}^{2}$-rich carbon $(\mathrm{a}-\mathrm{C})$ structure terminated with a 1-nm-thick film of graphene with a planar structure that is weakly oxidized mainly by $\mathrm{OH}$ groups (about 10 atom\%). A structure such as this is represented schematically in Fig. 16. ${ }^{(28)}$ The advantage of this coating compared with the traditional a-C:H is that tribochemical reactions are induced by the oleic acid lubricant. Consequently, an atomically smooth, partially oxidized, graphene-like structure created at the coating top surface affords a stable superlow-friction regime.

Under the effect of oleic acid, the graphene layer is partially oxidized via the tribochemical reaction. Eventually, friction occurs between the graphene oxide nanosheets when severe boundary/mixed lubrication conditions occur, leading to the ultralow regime (0.01-0.02). Figure 17 (a) shows the focused ion beam energy-filtering transmission electron microscope (FIB-EFTEM)

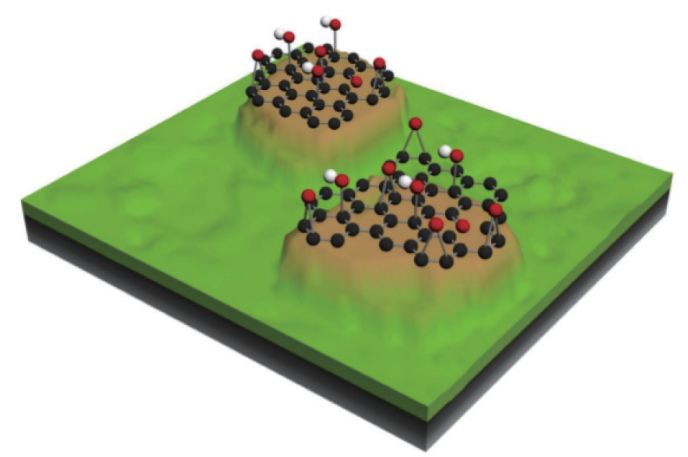

Fig. 16. (Color online) Schematic of the ta-C(T) surface after the friction test in the presence of oleic acid (according to PES and XANES analyses).

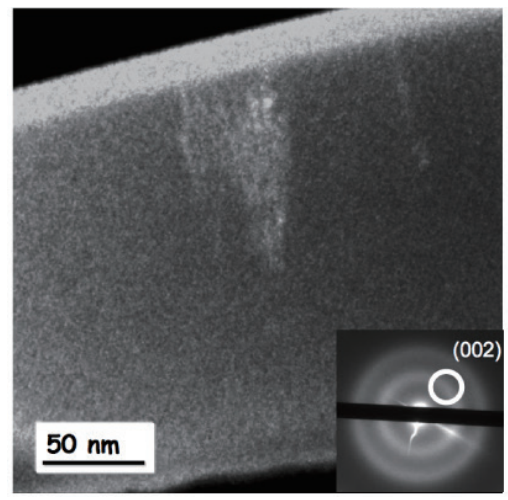

(a)

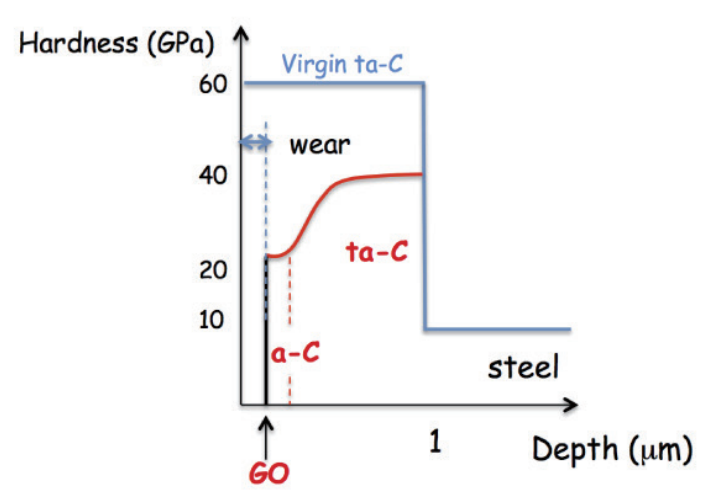

(b)

Fig. 17. (Color online) (a) TEM dark-field image of FIB cross section of ta-C coating after lubrication test in glycerol. The optical diffractogram shows the position of the diaphragm on the (002) ring. A sp ${ }^{2}$-carbon-rich film is visible at the top surface; (b) schematic view of surface chemistry and hardness changes occurring on the ta-C coating after the lubrication test. 
results for glycerol of the ta-C inside the wear scar, providing clear evidence of the formation of a 30-nm-thick sp ${ }^{2}$-rich amorphous layer on the top surface of the ta-C. ${ }^{(29)}$ This layer is not present in the pristine ta-C, which contains only approximately $30 \% \mathrm{sp}^{2}$ carbon and is formed during the running-in period. When the $\mathrm{sp}^{2}$-carbon content reaches a certain threshold, a graphene-like planar structure spontaneously forms on the a-C surface, and the smoother surface finishing that is obtained decreases the local pressure and may allow oleic acid molecules to reach the contact zone. Under the effect of oleic acid, the graphene-like layer is partially oxidized by the tribochemical reaction. Figure $17(\mathrm{~b})$ schematically shows the changes occurring in the surface chemistry, hybridization, and hardness of the ta-C coating after the lubrication test. ${ }^{(28)}$ Compared with the pristine ta-C coating, this hardness profile resulting from the self-adaptation of the coating is optimized for wear reduction and the presence of graphene oxide (GO) can decrease the friction efficiently. Comparatively, a softer hydrogenated DLC, a-C:H coating, does not exhibit this selfadaptation of the surface properties during friction.

Although accurate and direct experimental data are required to clarify this superlow-friction mechanism completely, sufficient experimentation is very time-consuming. Now, the advanced effect obtained by the simple combination of environment-friendly materials is expected to be applied on a large scale in industry in the near future.

\section{Conclusions}

The application of DLC coatings on sliding parts of automotive engine components such as valve lifters, piston rings, and fuel injectors has been increased to successfully improve wear resistance and to reduce friction. Henceforth, the optimum combination of DLC coatings with environment-friendly lubricants to generate the superlow friction must be found. The ta-C-ta-C pair with oleic acid lubrication reduced friction markedly to the superlow-friction level. It has been proposed that an atomically smooth graphene-like structure that is partially oxidized stabilizes the superlubricity regime at the topmost surface of the ta-C coating.

Judging from these studies, the potential of applying DLC coatings to address global environmental problems by exploiting the superlow-friction property is a promising endeavor.

\section{References}

1 A. Erdemir, O. Ozturk, M. Alzoubi, J. Woodfor, L. Ajayi, and G. Fenske: SAE Paper 2000-01-0518.

2 J. Andersson, R. A. Erck, and A. Erdemir: Wear 254 (2003) 1070.

3 F. Gao, A. Erdemir, and W. T. Tysoe: Tribology Let. 20 (2005) 221.

4 A. Erdemir and C. Donnet: J. Phys. D: Appl. Phys. 39 (2006) R311.

5 O. L. Eryilmaz and A. Erdemir: Wear 265 (2008) 244.

6 Y. Yasuda, M. Kano, Y. Mabuchi, and S. Abou: Research on diamond-like carbon coatings for low-friction valve lifters, SAE Paper 2003-01-1101, 2003.

7 M. Kano, Y. Yasuda, Y. Okamoto, Y. Mabuchi, T. Hamada, T. Ueno, J. Ye, S. Konishi, S. Takeshima, J. M. Martin, M. I. De Barros Bouchet, and T. Le Mogne: Tribology Lett. 18 (2005) 245.

8 Y. Mabuchi, T. Hamada, H. Izumi, Y. Yasuda, and M. Kano: SAE Paper 2007-01-1752.

9 T. T. Astrene: Tribol. Lubr. Technol. (March 2011) 22.

10 M. Woydt: J. ASTM Int., 8,6 Paper ID JAI 103368.

11 K. Holmberg, P. Andersson, and A. Erdemir: Tribology Int. 47 (2012) 221.

12 S. Toyoda: Tribology Online 2 (2007) 19.

13 T. Higuchi, Y. Mabuchi, H. Ichihara, T. Murata, and M. Moronuki: JSAE Proc., 299-20115707, 13.

14 M. Kennedy, S. Hoppe, and J. Esser: MTZ 0412014, vol. 75, 25. 
15 T. Shinyoshi, Y. Fuwa, and Y. Ozaki: JSAE20077103, SAE 2007-01-1969.

16 M. Masuko, T. Ono, S. Aoki, A. Suzuki, and H. Ito: Tribology Int. 82 (2015) 350.

17 A. Neville, A. Morina, T. Haque, and M. Voong: Tribology Int. 40 (2007) 1680.

18 M. Kalin, E. Roman, and J. Vizintin: Thin Solid Films 515 (2007) 3644.

19 K. T. Miklozic, F. Lockwood, and H. Spikes: Wear 265 (2008) 1893.

20 S. Equey, S. Roos, U. Mueller, R. Hauert, N. D. Spencer, and R. Crockett: Wear 264 (2008) 316.

21 T. Haque, A. Morina, and A. Neville: Surface Coatings Technol. 204 (2010) 4001.

22 B. Vengudusamy, J. H. Green, G. D. Lamb, and H. A. Spikes: Tribology Int. 44 (2011) 165.

23 M. Kano: New Diamond Frontier Carbon Technol. 16 (2006) 201.

24 C. Matta, L. Joly-Pottuz, M. I. De Barros Bouchet, J. M. Martin, M. Kano, Q. Zhang, and W. A. Goddard III: Physical Review, B 78 (2008) 085436.

25 S. Okuda, T. Dewa, and T. Sagawa: SAE 2007-01-1979, 1597.

26 M. Kano, J. M. Martin, K. Yoshida, and M. I. de. Barros Bouchet: Friction 2 (2014) 156.

27 H. Takikawa, K. Izumi, R. Miyano, and T. Sakakibara: Surface Coatings Technol. 163-164 (2003) 368.

28 M. I. De Barros Bouchet, J. M. Martin, J. Avila, M. Kano, K. Yoshida, T. Tsuruda, S. Bai, Y. Higuchi, N. Ozawa, M. Kubo, and M. Asensio: Sci. Rep. 7 (2017) SREP46394.

29 L. Joly-Pottuz, C. Matta, M. I. De Barros Bouchet, B. Vacher, J. M. Martin, and T. Sagawa: J. Appl. Phys. 102 (2007). 